\title{
Symposium review: Fat globules in milk and their structural modifications during gastrointestinal digestion*
}

\author{
Harjinder Singh† \\ Riddet Institute, Massey University, Palmerston North 4442, New Zealand
}

\begin{abstract}
The fat globules in milk are unique oil droplets that are stabilized by a specific and structurally complex membrane, the milk fat globule membrane (MFGM). In the last decade, excellent progress has been made on studying the structure of the milk fat globules and the MFGM and how common processing treatments affect these structures to deliver dairy products with improved functional properties. Although the digestion of milk fat to deliver energy and lipid-soluble nutrients is essential for survival of the neonate, there is little understanding of the complex processes involved. The structural alterations to fat globules during gastrointestinal processing affect the way in which milk fat is digested, absorbed, and metabolized. The packaging of these globules within the MFGM or in other forms may affect the bioaccessibility of raw or processed milk fat globules; in turn, this may affect access of the gastrointestinal enzymes to the globules and, therefore, may influence the rate and extent of lipid digestion. This review focuses on recent advances in understanding milk fat globules during gastrointestinal digestion, including the effects of processing on their bioavailability and the kinetics of lipid digestion. Possible effects of the dairy matrix on lipid digestion and physiological responses are briefly described.

Key words: milk, milk fat globule, milk fat globule membrane, gastrointestinal processing, lipid digestion
\end{abstract}

\section{INTRODUCTION: COMPOSITION AND STRUCTURE OF FAT GLOBULES}

Milk has evolved to meet the complete nutritional, and some defensive and other physiological requirements, of the neonate of the species. In addition to sup-

Received August 7, 2018.

Accepted November 12, 2018.

*Presented as part of the Joint MILK/Lactation Biology Symposium: Milk Globules, Vesicles, and Exosomes-Update, Origin, Structure, and Function at the ADSA Annual Meeting, Knoxville, Tennessee, June 2018.

†Corresponding author: h.singh@massey.ac.nz plying all the nutritional requirements of the neonate, many of the minor constituents of milk (e.g., oligosaccharides, immunoglobulins, metal-binding proteins, and enzymes) have protective roles. Compositionally, milk is a complex fluid containing several hundred molecular species. These include water, lipids, proteins, sugar (lactose), minerals, vitamins, hormones, enzymes, and miscellaneous compounds (O'Mahony and Fox, 2014).

Bovine milk contains approximately 3.5 to $5.0 \%$ lipids, which predominantly comprise triacylglycerols (98\%) and some minor components, such as diacylglycerols, monoacylglycerols, free fatty acids, phospholipids, and cholesterol. Milk fat acts as a concentrated source of energy for the neonate and is an important carrier of lipid-soluble constituents, such as lipid-soluble vitamins (A, D, E, and K) and several volatile flavor compounds. Some milk lipids, such as conjugated linoleic acid, sphingomyelin, and butyric acid, have been shown to exhibit physiological activities (Parodi, 2001).

The most interesting aspect of milk fat is the way in which the triacylglycerols are packaged in natural milk in the form of oil-in-water emulsions, commonly referred to as fat globules. The diameter of fat globules ranges from 0.1 to $15 \mu \mathrm{m}$, and they are surrounded and stabilized by a unique and complex layer, called the milk fat globule membrane (MFGM; Walstra, 1995; Mather, 2000). The unique structure and unique composition of the MFGM reflect the fat globule biosynthesis process in the mammary secretory cells. The MFGM is about 8 to $10 \mathrm{~nm}$ in thickness and contains multilayers consisting of phospholipids and proteins; a dense protein layer is located between the monolayer of phospholipids and proteins in contact with the triglyceride core and the inner face of the outer layer, which consists of a bilayer of phospholipids (Heid and Keenan, 2005). The outer phospholipid bilayer contains various glycoproteins, enzymes, phosphoproteins, and cholesterol (Dewettinck et al., 2008). The most abundant phospholipids are phosphatidylcholine, phosphatidylethanolamine, and sphingomyelin; phosphatidylserine and phosphatidylinositol are present in smaller proportions. The phospholipids are segregated between liquid-ordered domains that are particularly rich in sphingomyelin 
and cholesterol and are sometimes referred to as lipid rafts and liquid-disordered phases (Gallier et al., 2010; Lopez et al., 2010). The MFGM also contains 2 major neutral glycosphingolipids, glucosylceramide and lactosylceramide (Christie et al., 1987). Gangliosides are glycosphingolipids that comprise a ceramide and an oligosaccharide chain attached to 1 or more sialic acids and several sugars.

The MFGM contains more than 40 proteins consisting of several glycosylated proteins, including mucin 1 , butyrophilin (BTN), mucin 15, periodic acid Schiff 6/7 (PAS 6/7), and cluster of differentiation 36 (Mather, 2000). These proteins are mostly transmembrane proteins (mucin 1, mucin 15, BTN, and cluster of differentiation 36) except for PAS 6/7, which is loosely adsorbed at the surface (Dewettinck et al., 2008; Vanderghem et al., 2011). The other 3 major proteins are xanthine dehydrogenase/xanthine oxidase (XO), which is located within the proteinaceous layer of the MFGM; adipophilin, which is located in the inner face of the polar lipid bilayer; and fatty acid binding protein, which is located in the monolayer close to the lipid core (Vanderghem et al., 2011). The MFGM also contains about 25 enzymes and several other minor proteins (Mather, 2000; Spitsberg, 2005; Singh, 2006; Dewettinck et al., 2008).

The fat globules in milk are stable toward flocculation and coalescence because of a combination of electrostatic repulsion and steric repulsion provided by MFGM components. The zeta-potential of the fat globules is approximately $-10 \mathrm{mV}$, which indicates relatively low contributions from electrostatic repulsions. Partial coalescence of fat globules is known to occur upon storage of milk at low temperatures because of the formation of fat crystals, which can protrude from the globule surface and damage the MFGM (Walstra, 1995; Huppertz and Kelly, 2006). Because of their relatively wide distribution of sizes, the fat globules in fresh milk tend to undergo creaming during storage. The extent of creaming is considerably reduced by homogenization of the milk because a marked reduction occurs in the fat globule size after homogenization. This process also induces a simultaneous breakup of the MFGM, resulting in the adsorption of skim milk proteins at the fat globule surface to cover that newly created surface.

Temperature has a significant effect on the integrity and composition of the MFGM and consequently on the stability of fat globules. Heating milk above $60^{\circ} \mathrm{C}$ induces the denaturation of the MFGM proteins and their association with the whey proteins (Kim and Jimenez-Flores, 1995; Corredig and Dalgleish, 1996; Ye et al., 2004) via sulfhydryl-disulfide interchange reactions (Houlihan et al., 1992). This could involve the displacement of the original MFGM proteins by whey proteins, either by directly competing or because heating may cause the breakdown or reorganization of the MFGM, leaving gaps to allow whey proteins to adsorb to the newly exposed fat surface (Dalgleish and Banks, 1991). Ye et al. (2004) proposed that the thiol-disulfide interchange reactions were initiated by free thiol groups of the MFGM proteins, which became available for interaction at much lower temperatures than the denaturation temperature of the whey proteins ( $\beta-L G)$. The specific protein components of the MFGM that interact preferentially with whey proteins during heat treatment have not yet been identified. Ye et al. (2004) showed that XO and BTN denatured at lower heating temperatures (starting from $60^{\circ} \mathrm{C}, 10 \mathrm{~min}$ ) compared with PAS 6/7, which began to denature at $80^{\circ} \mathrm{C}$ (Ye et al., 2004). Interestingly, most of the major MFGM proteins (e.g., XO and BTN) remained anchored into the MFGM, although PAS 6/7 appeared to migrate into the serum phase during heating.

Heating has been shown to release phospholipids from the MFGM into the serum phase (Houlihan et al., 1992). Some of the MFGM material, particularly the phospholipids (20\%), may also be released into the milk serum upon the cooling of milk (Huppertz and Kelly, 2006). Freezing and thawing cause significant damage to the MFGM and destabilization of the fat globules. The rapid incorporation of air can also destabilize the MFGM, which is the basic mechanism for the manufacture of whipped cream and butter.

As summarized above, major advances have been made in understanding the synthesis of milk fat globules, the composition and structure of the MFGM, and how fat globules are influenced by various processing operations used in the dairy industry. The effect of fat globule modifications on the physical and chemical properties of dairy products has been extensively studied and reviewed (Evers, 2004; Singh, 2006; Lopez et al., 2015; Singh and Gallier, 2014, 2016).

In recent years, the physical and biochemical stability of milk fat globules after consumption has generated a great deal of research interest (Gallier et al., 2010, 2012; Ye et al., 2010, 2011; Singh and Gallier, 2014; Bourlieu and Michalski, 2015). There has been some progress on understanding how the MFGM and the physical structures of fat globules are modified during gastrointestinal (GI) digestion and how they influence the rates of lipid digestion. Knowledge of complex interactions between the fat globules, the MFGM, and the physiological components, such as mucin, gastric and intestinal enzymes (e.g., pepsin, trypsin, and lipases), and bile salts, is crucial to understanding the physiological behavior of milk during its transit through the GI tract. In this review, current advances in our understanding of the structures and the stability of fat 
globules from digestion viewpoints are highlighted, with a focus on the research carried out at the Riddet Institute laboratory at Massey University (Palmerston North, NZ).

\section{CHANGES IN FAT GLOBULES DURING GI DIGESTION}

The GI tract could be considered to be a multistage processing machine, with each stage contributing to the delivery of dietary nutrients efficiently at the site of absorption. The reader is referred to other reviews for details of the GI processing of foods (Singh et al., 2009; Bakala N'Goma et al., 2012; Singh and Gallier, 2014). It should be noted that there are major differences in lipid digestion between infants and adults, and these are mainly related to some of the digestive enzymes and gastric $\mathrm{pH}$ (see reviews by Abrahamse et al., 2012; Bourlieu et al., 2014). For example, infant fasting gastric $\mathrm{pH}$ is higher than that of an adult, which may influence gastric proteolysis. With regard to lipid digestion, gastric lipase activity is similar between infants and adults, but pancreatic lipase activity seems to vary between infants and adults. Little is known about the digestion behavior of milk fat globules in infants.

The digestion of food begins as early as in the oral cavity, through which food enters the digestive system; here, food is disintegrated into small particles and is mixed with saliva through the mechanical action of chewing, resulting in the formation of a bolus. The residence time of food in the oral cavity depends on its nature. Solid and semisolid foods are broken down until they reach a size that is small enough for easy swallowing, whereas liquids tend to be swallowed rapidly after mixing with saliva. Saliva is a complex biological fluid ( $\mathrm{pH}$ around 6.8) that contains water, electrolytes, salivary enzymes (such as $\alpha$-amylase and carbonic anhydrase), and several other proteins (immunoglobulins, antibacterial proteins, proline-rich proteins, lysozyme, and lactoferrin; Amado et al., 2005). Although the behavior of oil-in-water emulsions in the oral cavity, including the interactions of salivary components with the adsorbed layer on emulsion droplets, has been studied extensively (van Aken et al., 2007; Sarkar et al., 2009a), there is surprisingly little information on the behavior of milk fat globules in the oral environment. Smoczyński and Staniewski (2014) reported that the fat globules in raw milk showed extensive reversible flocculation upon mixing with artificial saliva, primarily because of depletion interaction, similar to that seen in emulsion droplets with low negative surface charge (Silletti et al., 2007). Milk is in contact with saliva only briefly before being swallowed; however, thicker dairy products such as cream and ice cream and solid dairy products such as cheese are in contact with saliva for a longer time. The interfacial behavior in the oral cavity of the fat globules in thicker dairy products needs to be further investigated.

The gastric environment is highly acidic, with a $\mathrm{pH}$ typically between 1 and 3, and contains various minerals and both proteolytic enzymes and lipolytic enzymes. Because of the action of pepsin, proteins are partially or fully hydrolyzed in the stomach, although some proteins are resistant to pepsin action. About 10 to $30 \%$ of lipids are hydrolyzed by gastric lipase into free fatty acids and diacylglycerols. Gastric pepsin would be expected to hydrolyze the MFGM protein layers (Ye et al., 2011; Gallier et al., 2012), as demonstrated in an SDS-PAGE analysis of the milk fat globules isolated from raw milk digested in an in vitro simulated gastric system; all MFGM proteins were hydrolyzed by pepsin into a range of peptides, but the rate of hydrolysis was different for different MFGM proteins. For instance, $\mathrm{XO}$ was hydrolyzed much faster than BTN, and PAS 6 and PAS 7 were hydrolyzed faster than BTN, but PAS 7 was more sensitive than PAS 6 (Figure 1).

The hydrolysis of interfacial MFGM protein was followed by an apparent flocculation of fat globules, as indicated by an increase in the average size $\left(d_{3,2}\right.$; volume-surface mean) of the milk fat globules with an increase in gastric digestion time (Ye et al., 2011). Similar to the flocculation observed in protein-stabilized emulsions (Sarkar et al., 2009b), the flocculation of the fat globules in the gastric environment may have arisen from the hydrolysis of charged MFGM proteins, resulting in a decrease in electrostatic repulsion. However, the zeta-potential did not support this possibility, as it did not change significantly during digestion. Examination of gastric digesta by confocal laser scanning microscopy showed that the flocculation of fat globules started at the early stages of digestion and seemed to be enhanced at long digestion times $(\geq 30 \mathrm{~min}$; Ye et al., 2011). The fat globules were linked through some protein or peptide material between the globules. A closer examination of the microstructure revealed that the fat globules were physically entrapped in the casein aggregate network and that they remained essentially intact during gastric digestion. It is known that the casein micelles in the serum phase of milk will aggregate with a reduction in the $\mathrm{pH}$ and hydrolysis by pepsin. Similar experiments using cream rather than milk confirmed that the fat globule size did not change during digestion. This suggests that some of the peptides hydrolyzed from the MFGM proteins remained at the globule surface and provided sufficient electrostatic repulsion and steric barriers to prevent coalescence of the fat globules. In addition, the phospholipid in the MFGM would be expected to remain at the surface and 


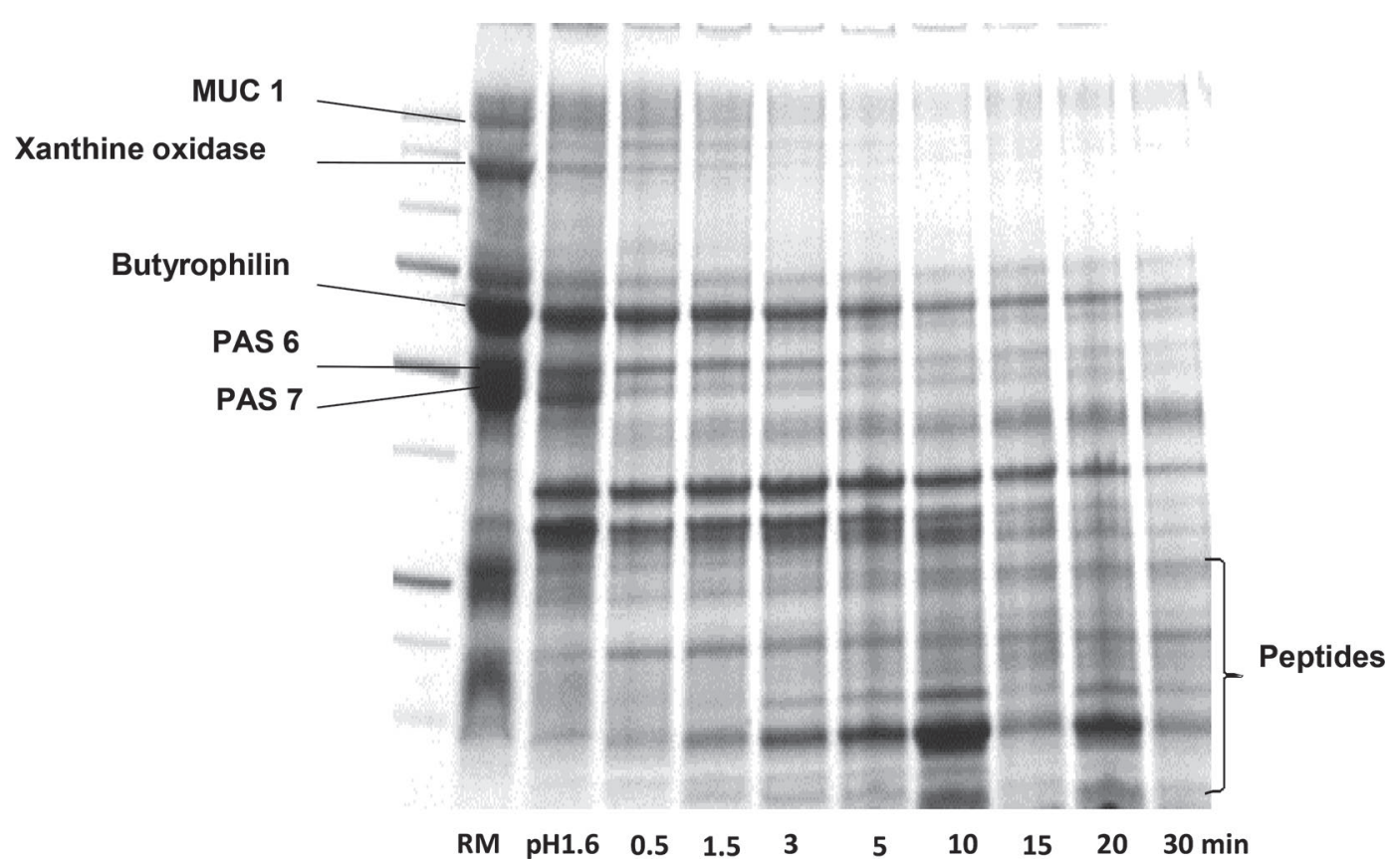

Figure 1. Sodium dodecyl sulfate-PAGE patterns of the milk fat globule membrane proteins obtained from the cream material of raw milk $(\mathrm{RM})$ samples incubated in simulated gastric fluid containing pepsin at $0.1 \mathrm{mg} / \mathrm{mL}$ as a function of digestion time. MUC $=$ mucin; PAS $=$ periodic acid Schiff. Reproduced with permission from Ye et al. (2011).

prevent the coalescence of the fat globules even in the absence of MFGM proteins.

Recent studies in our laboratory used a human gastric simulator to explore the structural changes in milk during gastric digestion (Ye et al., 2016, 2017). The human gastric simulator developed at the Riddet Institute is a sophisticated model that can closely mimic human gastric behavior and mimics many relevant factors of gastric physiology, such as a progressive acidification and emptying, that might significantly affect the bioaccessibility of nutrients.

As expected, the gradual increase in gastric acidity and pepsin hydrolytic activity induced coagulation of the casein micelles at a $\mathrm{pH}$ around 6.0 (well above the isoelectric point of caseins) in whole milk, and the fat globules became embedded in the clots as they formed. A longer residence time in the human gastric simulator resulted in an increased density of the clot, and the gradual breakdown of the proteins by pepsin allowed the release of the fat globules over time (Ye et al., 2016). Heat treatment of whole milk $\left(90^{\circ} \mathrm{C}\right.$ for 10 min to denature the whey proteins) before digestion resulted in softer clots in the human gastric simulator and a more rapid protein hydrolysis; as a consequence, the fat globules were released more rapidly (Figure 2). Comparison of the rates of fat globule release from the clots with the rates of the reduction in fat-free matter in the clots showed that the release of fat globules from the clots from both unheated milk and heated milk was linearly dependent on the breakdown of the protein in the clots.

Gallier et al. (2013a) studied the in vivo gastric digestion of bovine milk fat globules in cream derived from either raw milk or heated milk $\left(63^{\circ} \mathrm{C}\right.$ for $\left.30 \mathrm{~min}\right)$. Fasted rats were orally gavaged once with one of the cream preparations, and stomach chyme samples were collected from the rats posteuthanasia after $30 \mathrm{~min}, 2 \mathrm{~h}$, and $3 \mathrm{~h}$ postgavage. Cream was used to minimize casein coagulation in the stomach, as discussed above. The 2 cream samples presented similar initial protein profiles and showed rapid hydrolysis of MFGM proteins during digestion. Several peptides appeared after $30 \mathrm{~min}$ of gastric digestion. These results were generally similar to the observations made in the in vitro experiments (Gallier et al., 2012).

Free fatty acids, as a proportion of total fatty acids, increased throughout the 3 -h postprandial period, indicating lipolytic activity in the stomach. In rats, gastric lipase is absent but the acid-stable lingual lipase, produced by Von Ebner's glands, is present. This enzyme acts similarly to the human gastric lipase in the stomach, with a preference for fatty acids on $s n-3$ positions and short- and medium-chain fatty acids and has optimal activity at $\mathrm{pH} 5.0$ to 5.4 (Hamosh and Scow, 1973). Short- and medium-chain fatty acids were released more rapidly than long-chain fatty 
Milk before digestion

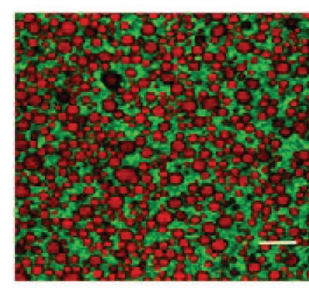

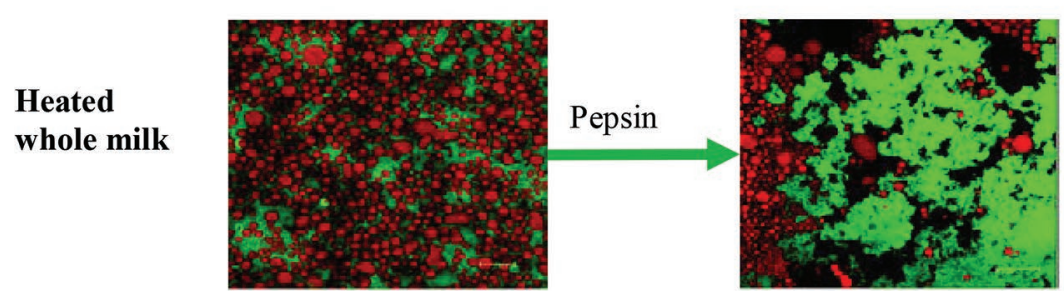

$20 \min$

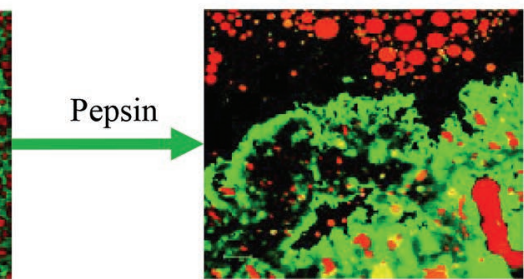

$80 \mathrm{~min}$
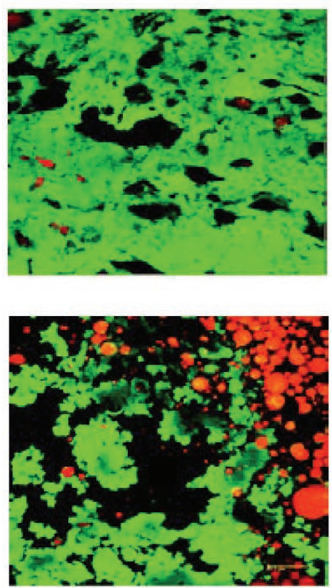

$220 \min$
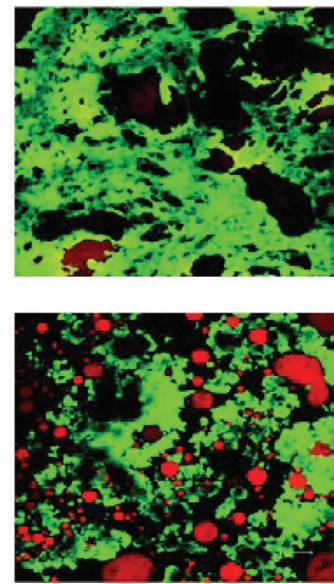

Figure 2. Confocal microscopy images of unheated whole milk and heated whole milk at different times during gastric digestion from 0 to 220 min. Red shows the fat, and green shows the protein. The scale bar in all images is $20 \mu \mathrm{m}$. Reproduced with permission from Ye et al. (2016).

acids (LCFA), and the latter were hydrolyzed to a greater degree from heated cream compared with raw cream. As mentioned earlier, heat treatment of milk causes interactions of whey proteins with the MFGM proteins, resulting in the presence of whey proteins at the MFGM. As the whey proteins in their adsorbed form are easily digested by pepsin, this may facilitate the access of gastric lipase to the triglyceride core by modifying the surface structure of the MFGM. This may explain the earlier appearance of free fatty acids at the surface of the fat globules in heated cream chyme than in raw cream chyme.

Confocal laser scanning microscopy of the gastric chyme showed that, after $30 \mathrm{~min}$ and $2 \mathrm{~h}$ of digestion, some liquid-ordered domains were present, indicating that the MFGM phospholipid trilayer may remain intact in the stomach (Brown and London, 1998). The MFGM protein fragments, which could still be intact at the surface of the fat globules in the chyme, as well as MFGM glycoproteins and phospholipids probably maintained the integrity of the MFGM during gastric digestion (Hamosh et al., 1999). This observation confirms those made in the in vitro studies discussed earlier (Ye et al., 2011; Gallier et al., 2012).

Using differential interference contrast microscopy, some interesting features were seen on the surface of the fat globules in the gastric chime (Figure 3). A few needle-shaped crystals were seen in the early stages of digestion, and the surface became more irregular with small protrusions at longer digestion times. The protrusions were similar in appearance to the spherical clusters observed by Pafumi et al. (2002) during gastric digestion of differently sized phospholipid-triolein emulsions by human gastric juice or purified human gastric lipase under close-to-physiological conditions. They speculated that these clusters trapped the gastric lipase, inhibiting its activity. They probably comprise the lipolytic products and phospholipids from the MFGM and the gastric mucosa, which tend to form lamellar phases at the oil-water interface. Berendsen and Blanchettemackie (1979) also observed lamellar structures at the surface of milk fat globules in the stomach of 10-d-old suckled rats. Some dark crystals observed in the lamellar phase could have been due to the presence of high-melting-point, fatty acid-containing lipolytic products.

In summary, it is evident that during gastric digestion, the surface structures of fat globules are modified considerably but without a drastic effect on their size. The gastric pepsin hydrolyzes the MFGM proteins, but the peptides remaining on the fat globule surface as well as phospholipids maintain the stability of the fat globules. The gastric lipase is able to penetrate the MFGM and spherical structures that are rich in free LCFA, and phospholipids are formed at the surface of the oil droplets. These structures could potentially trap the gastric lipase and limit its activity (Pafumi et al., 2002). The free fatty acids from the gastric lipolysis, peptides, and modified fat globules then move into the small intestine, where they are extensively altered to allow further lipid digestion and absorption.

The small intestine is the main site for the digestion and release of lipids and their conversion into an absorbable form via complex interactions with pancreatic and biliary secretions. The $\mathrm{pH}$ of the pancreatic juice is generally between 5 and 7 (Bakala N'Goma et al., 2012); it contains many enzymes, such as proteases and peptidases (e.g., trypsin, chymotrypsin, carboxypep- 


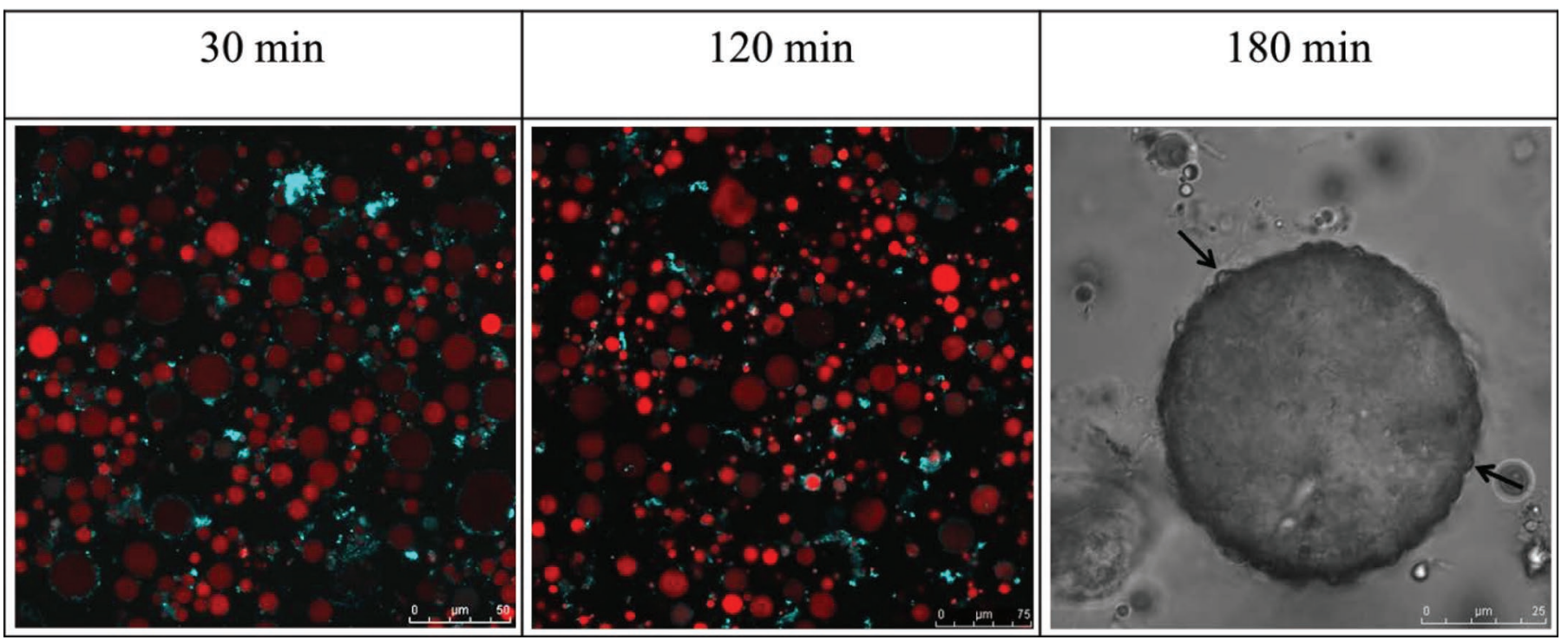

Figure 3. Confocal laser scanning microscopy (30 and $120 \mathrm{~min}$ ) and differential interference contrast (180 min) images of the gastric chyme collected from rats at 30,120, and 180 min after gavaging with cream derived from raw milk. The lipids were stained with Nile Red (red), and the proteins were stained with Fast Green FCF (blue). The black arrows point to spherical amorphous lipid protrusions. Scale bars $=50 \mu \mathrm{m}(30$ $\mathrm{min}), 75 \mu \mathrm{m}(120 \mathrm{~min})$, and $25 \mu \mathrm{m}$ (180 min). Adapted with permission from Gallier et al. (2013a).

tidases), lipases and esterases (e.g., pancreatic lipase, cholesterol esterase, phospholipase A2), and pancreatic amylases (Singh et al., 2009). Gastric-resistant proteins and peptides arriving from the stomach are further hydrolyzed by trypsin, chymotrypsin, and other proteases into AA, which are then absorbed. The lipids remaining after gastric digestion are further hydrolyzed primarily by pancreatic lipase (forming a complex with colipase) to release 2 free fatty acids and one 2-monoacylglycerol. Several other active lipases, such as phospholipase $\mathrm{A}_{2}$, cholesterol esterase, and pancreatic lipase-related protein, are also present in the pancreatic juice and contribute to the overall lipid digestion.

Biliary secretions containing bile salts play a crucial role in lipid digestion, as these salts are highly surface active and have the ability to adsorb and displace proteins and other biomaterials from an oil-water interface by orogenic mechanisms. Bile salts also solubilize lipolytic products into micelles and vesicles, which are the main transport vehicles of the lipolytic products. However, LCFA released as free fatty acids can form insoluble soaps with calcium, which may reduce their absorption and increase their fecal excretion. Any undigested material reaches the colon, where it is fermented by the gut microbiota (Knutson et al., 2010).

The changes in the ultrastructure of the milk fat globules in relation to lipid digestion have been studied mainly in in vitro digestion models with or without the gastric digestion step. In a simple in vitro standardized intestinal model, Ye et al. (2010) compared the behav- ior of the fat globules in raw milk, which had an intact MFGM, with that of the fat globules in recombined milk, in which the fat globules were coated by casein micelles and whey protein (i.e., no MFGM). These samples had similar initial average fat globule sizes; during the in vitro intestinal digestion, the average size increased dramatically during the early stages, followed by a rapid decrease and then a gradual increase with an increase in the digestion time. The zeta-potential was found to increase (in negative value) dramatically for both samples, but there were no differences in the rate of change in the zeta-potential between the raw milk sample and the recombined milk sample.

In the absence of bile extract, the rate of lipid digestion (estimated by the formation of free fatty acids during incubation in a simulated intestinal fluid) by pancreatic lipase was slower in the raw milk than in the recombined milk, but the final extent of lipid digestion after 290 min was similar in both samples. In the presence of bile extract $(5.0 \mathrm{mg} / \mathrm{mL})$, the rate of lipid digestion by pancreatic lipase was much faster and almost similar in both the raw milk and the recombined milk. However, the total amount of fatty acids released was slightly lower in the raw milk sample than in the recombined milk sample. It appeared that the bile salts either rapidly adsorbed or rapidly displaced (or both) the exiting biomaterials from the fat globules and largely eliminated the different properties of the original surfaces required for the adsorption of pancreatic lipase. It has been reported that the presence of bile 
salts at the fat globule surface promotes greater binding of pancreatic lipase to the interface by facilitating the formation of substrate clusters and thus enhancing lipid digestion (Wickham et al., 1998; Sarkar et al., 2016).

The products generated by the action of pancreatic lipase on milk triacylglycerols - namely, monoglyceride and fatty acid - are highly amphiphilic and have the tendency to self-assemble in the aqueous environment to form a variety of complex lyotropic liquid crystalline structures (Salentinig et al., 2011; Clulow et al., 2018). Using time-resolved small-angle X-ray scattering, Salentinig et al. (2013) showed the formation of highly ordered inverse hexagonal and cubic phases during the digestion of milk lipids. This included the initial formation of a persistent lamellar phase, the formation of small quantities of inverse micellar phases $(F d 3 m$ and emulsified microemulsion phases), the disappearance of the inverse micellar phase and the onset of an inverse hexagonal phase $\left(\mathrm{H}_{2}\right)$, and, finally, the diminution of the inverse hexagonal phase and the onset of bicontinuous cubic phases ( $P n 3 m$ and $I m 3 m$ phases).

Gallier et al. (2012) extended the work of Ye et al. (2011) and provided interesting insights into the ultrastructure of fat globules during the in vitro intestinal digestion of bovine milk. An in vitro sequential digestion model that simulated gastric and intestinal fasting conditions was used to monitor the physical, chemical, and structural changes of the fat globules from raw bovine milk. During in vitro intestinal digestion, the lipolytic products, released by the hydrolysis of the triglyceride core of the globules, led to destabilization and coalescence of the fat globules. Confocal laser scanning microscopy revealed that these products accumulated at the surface of the fat globules, forming liquid crystalline lamellae at a sufficient ratio of lipolytic products to bile salts. In the aqueous phase, several disk-shaped bile salt-phospholipid micelles were seen; these were probably involved in transporting the lipolytic products (Gallier et al., 2012).

Continuing their in vivo gastric digestion studies, Gallier et al. (2013b) examined the upper and lower small intestinal contents of rats gavaged with different cream preparations. As expected, the gastric-resistant proteins and peptides present in the stomach chyme from rats fed different cream preparations were almost fully hydrolyzed by the intestinal proteases in the upper and lower small intestines. Significant differences in concentrations of some of the fatty acids between the upper and lower intestinal digesta were observed; higher proportions of longer chain (10 or more carbon units) fatty acids were present in the digesta of rats gavaged with cream from raw milk than in the digesta of rats gavaged with cream obtained from heated milk.
Confocal laser scanning microscopy and transmission electron microscopy were used to investigate the structural changes during digestion. Examination of the upper small intestinal contents showed the presence of liquid crystalline lamellar phases surrounding most of the fat globules and crystals of fatty acid soaps in the aqueous phase. These liquid crystalline lamellae were probably composed of bile salts, phospholipids, and lipolytic products. They are considered to be formed at low concentrations of bile salts and are due to swelling of the amphiphilic lipolytic products, creating water spacing between the lamellae. The lamellar shell surrounding the fat globules seemed to crack open, expelling some droplets from the fat globules, leaving behind a crystalline shell (Figure 4). These expelled droplets were probably stabilized by the adsorption of bile salts and phospholipids. At concentrations near their critical micellar concentration, bile salts are able to solubilize the lipolytic products into mixed micelles or vesicles. Short- and medium-chain fatty acids are readily solubilized in vesicles and are absorbed through the intestinal walls (Michalski et al., 2006). In contrast, LCFA tend to accumulate at the oil-water interface because of their poor solubility in water at the intestinal $\mathrm{pH}$. They are eventually solubilized into micelles and vesicles or are precipitated to form insoluble soaps in the presence of calcium (Carey et al., 1983). The LCFA at the $s n-1$ and $s n-3$ positions are considered to be less absorbed as they are saponified as calcium soaps, but LCFA at the $s n-2$ position are easily absorbed as 2-monoglycerides (Michalski, 2009).

In all digesta samples, some dark round spots and needle-shaped crystals were seen; these were possibly a mixture of fatty acid crystals and fatty acid soap crystals, as they can coexist at physiological pH (Cistola et al., 1988). Needle-shaped crystals of $\geq 20 \mu \mathrm{m}$ in size were also observed by Knutson et al. (2010) in human jejunum aspirates after the ingestion of vegetable oil emulsions and were found to comprise LCFA in their acid form. Galactolipids and phospholipids, both MFGM components, are known to play a role in crystal formation (Knutson et al., 2010).

\section{EFFECT OF DAIRY MATRIX ON LIPID DIGESTION AND PHYSIOLOGICAL RESPONSES}

Until recently, milk fat has been associated with many negative health effects, mainly because of observations relating to its relatively high SFA content, which may lead to increased low-density lipoprotein (LDL) cholesterol and thus an increased risk of cardiovascular disease (Artaud-Wild et al., 1993). However, recent findings indicate that the link between the SFA content and cardiovascular disease is not as simple because the lipid 

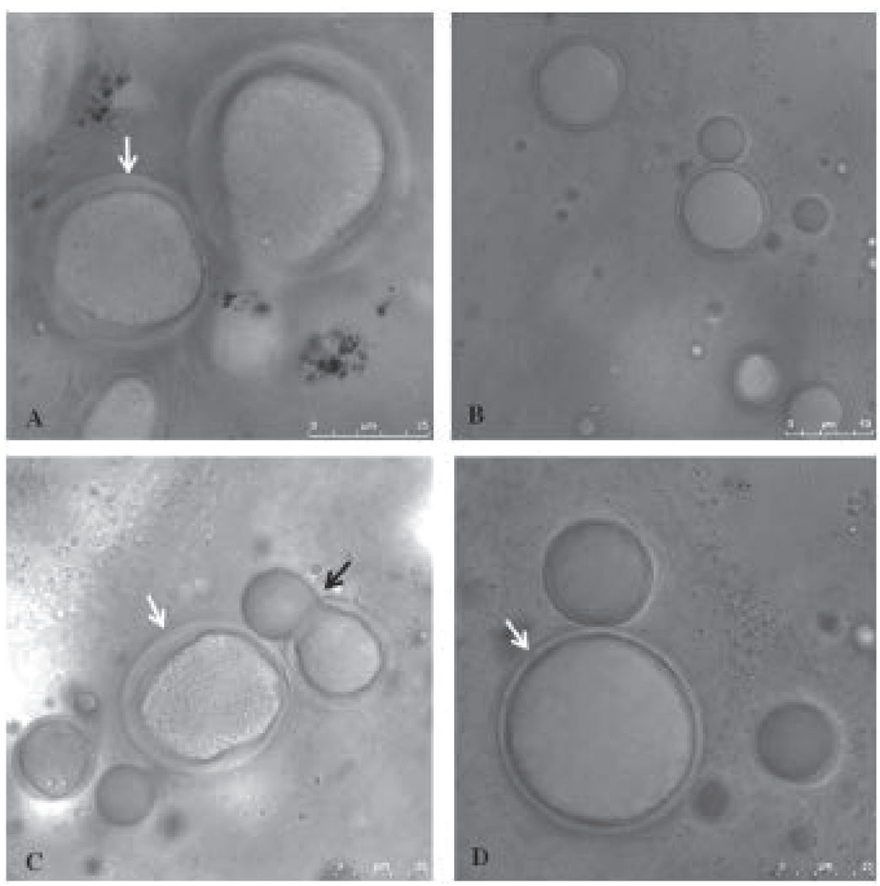

Figure 4. Differential interference contrast images of upper (A and $\mathrm{C}$ ) and lower (B and $\mathrm{D})$ small intestinal digesta from rats fed raw milk. White arrows indicate liquid-lamellar phases and the black arrows indicate oil coming out of these phases. Scale bars $=10 \mu \mathrm{m}$ (A and D) and $50 \mu \mathrm{m}$ (B and C). Reproduced with permission from Gallier et al. (2013).

composition and structure and the presence of other nutrients (e.g., phospholipids, milk proteins, calcium, and vitamin $\mathrm{D}$ ) in milk products could affect the lipoprotein metabolism (Lordan et al., 2018). The physical state and structure of fat globules vary widely in different milk products, such as cheese, yogurt, ice cream, butter, and cream. The matrix structure (whether solid, semisolid, or liquid) and the physical characteristics of these products have been shown to influence the release and rate of digestion of fat globules in in vitro GI digestion models (Lamothe et al., 2017; Fardet et al., 2018). Fruekilde and Hoy (2004) examined the effects of different dairy products (cream cheese, cream, sour cream, butter, and melted butter) on lipid absorption at the lymphatic level in rats. The consumption of cream and sour cream caused a faster absorption of the lipid fraction at the lymphatic level compared with the consumption of cream cheese, butter, and melted butter, and the response of cream cheese was similar to that of butter and melted butter. Because the fatty acid composition of these dairy systems differs only slightly, this indicates that the structure of the emulsion, the particle size, and possibly the protein content influenced the digestion and absorption of the fat and probably affected the lipemic response.
Several human intervention studies have shown that various milk products differ markedly in the way they influence blood lipid and cholesterol profiles and the other biomarkers of cardiovascular disease. A recent meta-analysis of randomized controlled trials (de Goede et al., 2015) indicates that fat consumed in the form of butter has a different effect than the fat delivered in the cheese matrix, supporting the important role of a dairy matrix in lipid digestion and absorption. Clemente et al. (2003) showed that in type 2 diabetic subjects, the ingestion of an isoenergetic diet including milk (liquid), butter (solid), or cheese (semisolid) had no effect on the duration of postprandial lipemia. However, the triglyceride peak was delayed after ingestion of the butterbased diet, probably because of the presence of smaller fat globules in milk and cheese, which are thus digested at a faster rate than butter fat. The gastric emptying rate was greater with the cheese-based diet than with the milk-based diet. Drouin-Chartier et al. (2017) reported the effect of the cheese matrix on postprandial lipemia in healthy humans. The subjects consumed $33 \mathrm{~g}$ of fat from a firm cheese (young Cheddar), a soft cream cheese (cream cheese), or butter (control), which was incorporated into standardized meals that were matched for macronutrient content. They reported significantly higher triglyceride response from the consumption of cream cheese than from the consumption of butter and Cheddar cheese. The fat globule size and the organization within the cheese matrices may have modulated the postprandial lipid response: the diameter of a fat globule from cream cheese was approximately one-sixth the size of a Cheddar cheese lipid droplet, possibly increasing the contact surface for pancreatic lipase.

Tholstrup et al. (2004) compared the effects of the same amount of milk fat consumed in the form of cheese, milk, or butter in whole diets; the diets had the same amounts of protein and lactose but not calcium. No significant differences in blood lipids were found between cheese and milk, but butter caused a significant increase in blood LDL cholesterol compared with cheese; the effect of milk was intermediate. Soerensen et al. (2014) carried out a human intervention study in which cheese and milk were consumed in quantities that provided similar amounts of fat, protein, and calcium. Compared with the butter control diet, in which protein and fat (but not calcium) were balanced with the amounts in the cheese and milk diets, both cheese and milk attenuated the increase in LDL cholesterol compared with butter. These studies indicate the possible effect of calcium on fat absorption and LDL cholesterol.

As discussed earlier, free fatty acids produced by pancreatic lipase are precipitated in the presence of calcium as largely insoluble calcium-fatty acid soaps (Jenkins and Palmquist, 1982). Another possible mechanism is 
the precipitation of calcium and phosphate as insoluble amorphous calcium phosphate, which adsorbs bile acids and free fatty acids and increases their fecal excretion (Govers et al., 1994). This could cause a regeneration of bile acids from hepatic cholesterol and thereby result in a lowering of plasma cholesterol concentrations.

Intact MFGM as a part of the fat globules or as free released fragments has also been shown to affect the fecal fat excretion in humans. Some studies have suggested that the MFGM could in fact reduce or prevent the increase in fasting total cholesterol, LDL cholesterol, and triacylglycerols, usually suspected to be caused by SFA intake (Conway et al., 2013; Rosqvist et al., 2015). Chung et al. (2013) suggested that the MFGM reduces intestinal cholesterol absorption through the inhibition of cholesterol micellar solubility, probably because of the presence of sphingomyelin (Conway et al., 2010). Because sphingomyelin is not completely hydrolyzed in the human small intestine, it can form sphingomyelincholesterol complexes, which may limit cholesterol absorption (Eckhardt et al., 2002). However, such an effect was not confirmed in human studies that measured markers of intestinal fat absorption (Conway et al., 2013).

\section{CONCLUSIONS}

The structure of the bovine milk fat globule and its membrane has been a subject of great interest since the 1970s. The last decade has seen the application of several new techniques to probe the synthesis of milk fat globules, the composition and the structure of the MFGM, and how fat globules are influenced by various processing operations. Recent studies on understanding the structural changes in milk fat globules during GI digestion have revealed that the native fat globules remain stable under gastric conditions, although pepsin is able to hydrolyze most of the MFGM proteins. Some of the MFGM proteins appear to be resistant to gastric digestion. In contrast, homogenized milk fat globules, coated with caseins, aggregate readily under gastric conditions. Interestingly, it has been discovered recently that the surrounding curd structures formed by the coagulation of casein in the gastric environment have a profound effect on the rate of emptying of fat globules and hence the kinetics of lipid digestion. Fat globules in natural milk show longer residence times in the stomach, as they remain entrapped in a cohesive casein network clot. The curds formed by homogenized and heat-treated milk have a more crumbled and porous structure, and the fat globules are released into the small intestine more rapidly. Under intestinal conditions, the lipolytic products, released from the hydrolysis of the triglyceride core of the globules by the action of pancreatic lipase, lead to destabilization and coalescence of the globules. These droplets are surrounded by liquid crystalline lamellar phases, which are then solubilized as multilamellar vesicles involving bile salts. The actual state and surface structures of the fat globules in the intestinal environment are unknown. Further studies on the fate of undigested MFGM proteins and peptides and the phospholipid components, particularly sphingomyelin, of the MFGM are required.

There is increasing evidence that the complex physical structure and matrix have implications for digestion, absorption, and metabolism and that different dairy products seem to exert various health effects. This is important with respect to lipid digestion and bioavailability, and further work on the state of the fat globules in different dairy products and their modifications during digestion is required. There is a need for standardized models for in vitro studies, as it is often difficult to compare the results from different in vitro models (static, semidynamic, or dynamic) and from the use of different concentrations of digestive enzymes and different compositions of gastric and pancreatic juices. Many of the in vitro findings need to be validated in in vivo animal studies and human clinical trials. The development of more advanced in vitro models will help in obtaining a clearer picture of the fate of the fat globules and the MFGM within the GI tract.

\section{ACKNOWLEDGMENTS}

The author acknowledges Aiqian Ye and Sophie Gallier (Riddet Institute, Massey University) for their contributions to the work reported in this review. This work was supported by funding from the New Zealand Ministry of Education (Wellington) through the Centre of Research Excellence funding.

\section{REFERENCES}

Abrahamse, E., M. Minekus, G. A. van Aken, B. van de Heijning, J. Knol, N. Bartke, R. Oozeer, E. M. van der Beek, and T. Ludwig. 2012. Development of the digestive system: Experimental challenges and approaches of infant lipid digestion. Food Dig. 3:63-77.

Amado, F. M., R. M. Vitorino, P. M. Domingues, M. J. C. Lobo, and J. A. R. Duarte. 2005. Analysis of the human saliva proteome. Expert Rev. Proteomics 2:521-539.

Artaud-Wild, S. M., S. Connor, G. Sexton, and W. E. Connor. 1993. Differences in coronary mortality can be explained by differences in cholesterol and saturated fat intakes in 40 countries but not in France and Finland. A paradox. Circulation 88:2771-2779.

Bakala N'Goma, J. C., S. Amara, K. Dridi, V. Jannin, and F. Carrière. 2012. Understanding the lipid-digestion processes in the GI tract before designing lipid-based drug-delivery systems. Ther. Deliv. 3:105-124.

Berendsen, P. B., and E. J. Blanchette-Mackie. 1979. Milk lipid absorption and chylomicron production in the sucking rat. Anat. Rec. 195:397-414.

Bourlieu, C., O. Menard, and K. Bouzerzou.rMandalari, G., A. Macierzanka, A. R. Mackie, and D. Dupont. 2014. Specificity of infant 
digestive conditions: Some clues for developing relevant in vitro models. Crit. Rev. Food Sci. Nutr. 54:1427-1457.

Bourlieu, C., and M.-C. Michalski. 2015. Structure-function relationship of the milk fat globule. Curr. Opin. Clin. Nutr. Metab. Care 18:118-127.

Brown, D. A., and E. London. 1998. Functions of lipid rafts in biological membranes. Annu. Rev. Cell Dev. Biol. 14:111-136.

Carey, M. C., D. M. Small, and C. M. Bliss. 1983. Lipid digestion and absorption. Annu. Rev. Physiol. 45:651-677.

Christie, W. W., R. C. Noble, and G. Davies. 1987. Phospholipids in milk and dairy products. Int. J. Dairy Technol. 40:10-12.

Chung, R. W., A. Kamili, S. Tandy, J. M. Weir, R. Gaire, G. Wong, P. J. Meikle, J. S. Cohn, and K. A. Rye. 2013. Dietary sphingomyelin lowers hepatic lipid levels and inhibits intestinal cholesterol absorption in high-fat-fed mice. PLoS One 8:e55949.

Cistola, D. P., J. A. Hamilton, D. Jackson, and D. M. Small. 1988. Ionization and phase behavior of fatty acids in water: Application of the Gibbs phase rule. Biochemistry 27:1881-1888.

Clemente, G., M. Mancini, F. Nazzaro, G. Lasorella, A. Rivieccio, A. M. Palumbo, A. A. Rivellese, L. Ferrara, and R. Giacco. 2003. Effects of different dairy products on postprandial lipemia. Nutr. Metab. Cardiovasc. Dis. 13:377-383.

Clulow, A. J., M. Salim, A. Hawley, and B. J. Boyd. 2018. A closer look at the behaviour of milk lipids during digestion. Chem. Phys. Lipids 211:107-116.

Conway, V., P. Couture, C. Richard, S. F. Gauthier, Y. Pouliot, and B. Lamarche. 2013. Impact of buttermilk consumption on plasma lipids and surrogate markers of cholesterol homeostasis in men and women. Nutr. Metab. Cardiovasc. Dis. 23:1255-1262.

Conway, V., S. Gauthier, and Y. Pouliot. 2010. Effect of cream pasteurization, microfiltration and enzymatic proteolysis on in vitro cholesterol-lowering activity of buttermilk solids. Dairy Sci. Technol. 90:449-460.

Corredig, M., and D. G. Dalgleish. 1996. Effect of different heat treatments on the strong binding interactions between whey proteins and milk fat globules in whole milk. J. Dairy Res. 63:441-449.

Dalgleish, D. G., and J. M. Banks. 1991. The formation of complexes between serum proteins and fat globules during heating of whole milk. Milchwissenschaft 46:75-78

de Goede, J., J. M. Geleijnse, E. L. Ding, and S. S. Soedamah-Muthu. 2015. Effect of cheese consumption on blood lipids: A systematic review and meta analysis of randomized controlled trials. Nutr. Rev. 73:259-275.

Dewettinck, K., R. Rombaut, N. Thienpont, T. T. Le, K. Messens, and J. Van Camp. 2008. Nutritional and technological aspects of milk fat globule membrane material. Int. Dairy J. 18:436-457.

Drouin-Chartier, J.-P., A. J. Tremblay, J. Maltais-Giguère, A. Charest, L. Guinot, L.-E. Rioux, S. Labrie, M. Britten, B. Lamarche, S. L. Turgeon, and P. Couture. 2017. Differential impact of the cheese matrix on the postprandial lipid response: A randomized, crossover, controlled trial. Am. J. Clin. Nutr. 106:1358-1365.

Eckhardt, E. R., D. Q. Wang, J. M. Donovan, and M. C. Carey. 2002 Dietary sphingomyelin suppresses intestinal cholesterol absorption by decreasing thermodynamic activity of cholesterol monomers. Gastroenterology 122:948-956.

Evers, J. M. 2004. The milk fat globule membrane-Compositional and structural changes post secretion by the mammary secretory cell. Int. Dairy J. 14:661-674.

Fardet, A., D. Dupont, L. E. Rioux, and S. L. Turgeon. 2018. Influence of food structure on dairy protein, lipid and calcium bioavailability: A narrative of evidence. Crit. Rev. Food Sci. Nutr. https://doi .org/10.1080/10408398.2018.1435503.

Fruekilde, M. B., and C. E. Hoy. 2004. Lymphatic fat absorption varies among rats administered dairy products differing in physiochemical properties. J. Nutr. 134:1110-1113.

Gallier, S., J. Cui, T. D. Olson, S. M. Rutherfurd, A. Ye, P. J. Moughan, and H. Singh. 2013a. In vivo digestion of bovine milk fat globules: Effect of processing and interfacial structural changes. I. Gastric digestion. Food Chem. 141:3273-3281.

Gallier, S., D. Gragson, R. Jimenez-Flores, and D. W. Everett. 2010. Using confocal laser scanning microscopy to probe the milk fat globule membrane and associated proteins. J. Agric. Food Chem. 58:4250-4257.

Gallier, S., A. Ye, and H. Singh. 2012. Structural changes of bovine milk fat globules during in vitro digestion. J. Dairy Sci. 95:3579 3592 .

Gallier, S., X. Q. Zhu, S. M. Rutherfurd, A. Ye, P. J. Moughan, and H. Singh. 2013b. In vivo digestion of bovine milk fat globules: Effect of processing and interfacial structural changes. II. Upper digestive tract digestion. Food Chem. 141:3215-3223.

Govers, M. J., D. S. Termont, G. A. Van Aken, and R. Van der Meer. 1994. Characterization of the adsorption of conjugated and unconjugated bile acids to insoluble, amorphous calcium phosphate. J. Lipid Res. 35:741-748.

Hamosh, M., J. A. Peterson, T. R. Henderson, C. D. Scallan, R. Kiwan, R. L. Ceriani, M. Armand, N. R. Mehta, and P. Hamosh. 1999. Protective function of human milk: The milk fat globule. Semin. Perinatol. 23:242-249.

Hamosh, M., and R. O. Scow. 1973. Lingual lipase and its role in digestion of dietary lipid. J. Clin. Invest. 52:88-95.

Heid, H. W., and T. W. Keenan. 2005. Intracellular origin and secretion of milk fat globules. Eur. J. Cell Biol. 84:245-258.

Houlihan, A. V., P. A. Goddard, B. J. Kitchen, and C. J. Masters. 1992. Changes in structure of the bovine milk fat globule membrane on heating whole milk. J. Dairy Res. 59:321-329.

Huppertz, T., and A. L. Kelly. 2006. Physical chemistry of milk fat globules. Pages 173-212 in Advanced Dairy Chemistry: Lipids. 3rd ed. Vol. 2. P. F. Fox and P. L. H. McSweeney, ed. Springer Science and Business Media, New York, NY

Jenkins, T. C., and D. L. Palmquist. 1982. Effect of added fat and calcium on in vitro formation of insoluble calcium fatty acid soaps and cell wall digestibility. J. Anim. Sci. 55:957-963.

Kim, H. H. Y., and R. Jimenez-Flores. 1995. Heat-induced interactions between the proteins of milk fat globule membrane and skim milk J. Dairy Sci. 78:24-35.

Knutson, L., D. J. Koenders, H. Fridblom, A. Viberg, A. Sein, and H. Lennernas. 2010. Gastrointestinal metabolism of a vegetable-oil emulsion in healthy subjects. Am. J. Clin. Nutr. 92:515-524.

Lamothe, S., N. Remillard, J. Tremblay, and M. Britten. 2017. Influence of dairy matrices on nutrient release in a simulated gastrointestinal environment. Food Res. Int. 92:138-146.

Lopez, C., C. Cauty, and F. Guyomarc'h. 2015. Organization of lipids in milks, infant milk formulas and various dairy products: Role of technological processes and potential impacts. Dairy Sci. Technol. 95:863-893.

Lopez, C. M. N. Madec, and R. Jimenez-Flores. 2010. Lipid rafts in the bovine milk fat globule membrane revealed by the lateral segregation of phospholipids and heterogeneous distribution of glycoproteins. Food Chem. 120:22-33.

Lordan, R., A. Tsoupras, B. Mitra, and I. Zebetalkis. 2018. Dairy fats and cardiovascular disease: Do we really need to be concerned? Foods $7: 1-34$

Mather, I. H. 2000. A review and proposed nomenclature for major proteins of the milk-fat globule membrane. J. Dairy Sci. 83:203247.

Michalski, M. C. 2009. Specific molecular and colloidal structures of milk fat affecting lipolysis, absorption and postprandial lipemia. Eur. J. Lipid Sci. Technol. 111:413-431.

Michalski, M. C., A. F. Soares, C. Lopez, N. Leconte, V. Briard, and A. Geloen. 2006. The supramolecular structure of milk fat influences plasma triacylglycerols and fatty acid profile in the rat. Eur. J. Nutr. 45:215-224

O'Mahony, J. A., and P. F. Fox. 2014. Milk: An overview. Pages 19-73 in Milk Proteins. 2nd ed. H. Singh, M. Boland, and A. Thompson, ed. Academic Press, San Diego, CA.

Pafumi, Y., D. Lairon, P. L. de la Porte, C. Juhel, J. Storch, M. Hamosh, and M. Armand. 2002. Mechanisms of inhibition of triacylglycerol hydrolysis by human gastric lipase. J. Biol. Chem. 277:28070-28079.

Parodi, P. W. 2001. Cow's milk components with anti-cancer potential. Aust. J. Dairy Technol. 56:65-73. 
Rosqvist, F., A. Smedman, H. Lindmark-Mansson, M. Paulsson, P. Petrus, S. Straniero, M. Rudling, I. Dahlman, and U. Riserus. 2015. Potential role of milk fat globule membrane in modulating plasma lipoproteins, gene expression, and cholesterol metabolism in humans: A randomized study. Am. J. Clin. Nutr. 102:20-30.

Salentinig, S., S. Phan, J. Khan, A. Hawley, and B. J. Boyd. 2013. Formation of highly organized nanostructures during the digestion of milk. ACS Nano 7:10904-10911.

Salentinig, S., L. Sagalowicz, M. E. Leser, C. Tedeschi, and O. Glatter. 2011. Transitions in the internal structure of lipid droplets during fat digestion. Soft Matter 7:650-661.

Sarkar, A., K. Goh, P. Singh, and H. Singh. 2009b. Behaviour of an oil-in-water emulsion stabilized by beta-lactoglobulin in an in vitro gastric model. Food Hydrocoll. 23:1563-1569.

Sarkar, A., K. K. T. Goh, and H. Singh. 2009a. Colloidal stability and interactions of milk-protein-stabilized emulsions in an artificial saliva. Food Hydrocoll. 23:1270-1278.

Sarkar, A., A. Ye, and H. Singh. 2016. On the role of bile salts in the digestion of emulsified lipids. Food Hydrocoll. 60:77-84.

Silletti, E., M. H. Vingerhoeds, W. Norde, and G. A. van Aken. 2007. The role of electrostatics in saliva-induced emulsion flocculation. Food Hydrocoll. 21:596-606.

Singh, H. 2006. The milk fat globule membrane-A biophysical system for food applications. Curr. Opin. Colloid Interface Sci. 11:154163.

Singh, H., and S. Gallier. 2014. Processing of food structures in the gastrointestinal tract and physiological responses. Pages 51-81 in Food Structures, Digestion and Health. M. Boland, M. Golding, and H. Singh, ed. Academic Press, San Diego, CA.

Singh, H., and S. Gallier. 2016. Nature's complex emulsion: The fat globules of milk. Food Hydrocoll. 68:81-89.

Singh, H., A. Ye, and D. Horne. 2009. Structuring food emulsions in the gastrointestinal tract to modify lipid digestion. Prog. Lipid Res. 48:92-100.

Smoczyński, M., and B. Staniewski. 2014. Saliva-induced flocculation of milk fat globules studied by image analysis. Agric. Food $2: 542-548$

Soerensen, K. V., T. K. Thorning, A. Astrup, M. Kristensen, and J. K. Lorenzen. 2014. Effect of dairy calcium from cheese and milk on fecal fat excretion, blood lipids, and appetite in young men. Am. J. Clin. Nutr. 99:984-991.

Spitsberg, V. L. 2005. Bovine milk fat globule membrane as a potential nutraceutical. J. Dairy Sci. 88:2289-2294.

Tholstrup, T., C. E. Hoy, L. N. Andersen, R. D. Christensen, and B. Sandstrom. 2004. Does fat in milk, butter and cheese affect blood lipids and cholesterol differently? J. Am. Coll. Nutr. 23:169-176.

van Aken, G. A., M. H. Vingerhoeds, and E. H. A. de Hoog. 2007. Food colloids under oral conditions. Curr. Opin. Colloid Interface Sci. 12:251-262.

Vanderghem, C., F. Francis, S. Danthine, C. Deroanne, M. Paquot, E. De Pauw, and C. Blecker. 2011. Study on the susceptibility of the bovine milk fat globule membrane proteins to enzymatic hydrolysis and organization of some of the proteins. Int. Dairy J. $21: 312-318$.

Walstra, P. 1995. Physical chemistry of milk fat globules. Pages 131178 in Advanced Dairy Chemistry: Lipids. 2nd ed. Vol. 2. P. F. Fox, ed. Chapman and Hall, London, UK.

Wickham, M., M. Garrood, J. Leney, P. D. G. Wilson, and A. FilleryTravis. 1998. Modification of a phospholipid stabilized emulsion interface by bile salt: Effect on pancreatic lipase activity. J. Lipid Res. 39:623-632.

Ye, A., J. Cui, D. Dalgleish, and H. Singh. 2016. The formation and breakdown of structured clots from whole milk during gastric digestion. Food Funct. 7:4259-4266.

Ye, A., J. Cui, D. Dalgleish, and H. Singh. 2017. Effect of homogenization and heat treatment on the behavior of protein and fat globules during gastric digestion of milk. J. Dairy Sci. 100:36-47.

Ye, A., J. Cui, and H. Singh. 2010. Effect of the fat globule membrane on in vitro digestion of milk fat globules with pancreatic lipase. Int. Dairy J. 20:822-829.

Ye, A., J. Cui, and H. Singh. 2011. Proteolysis of milk fat globule membrane proteins during in vitro gastric digestion of milk. J. Dairy Sci. 94:2762-2770.

Ye, A. Q., H. Singh, M. W. Taylor, and S. Anema. 2004. Interactions of whey proteins with milk fat globule membrane proteins during heat treatment of whole milk. Lait 84:269-283. 